Conclusions: MG was observed in patients with various rheumatic disorders, with SS being the most common type. The presence of MG might associated with higher disease activity. The development of haematological neoplasias including $\mathrm{MM}$ and lymphoma was seen in this setting. Therefore, we recommend the screening for $M G$ and close monitoring for potential malignant transformation in patients with rheumatic diseases as needed.

Disclosure of Interest: None declared

DOI: 10.1136/annrheumdis-2018-eular.7575

\section{AB1166 THE ASSOCIATION OF THE EARLY ONSET OF REMITTING SERONEGATIVE SYMMETRICAL SYNOVITIS WITH PITTING OEDEMA (RS3PE) SYNDROME WITH DIPEPTIDYL PEPTIDASE-4 (DPP4) INHIBITOR}

Y. Yoshioka, M. Mitsuhashi, A. Kato, D. Kanai, A. Suda, S. Nagaoka. Rheumatology, Yokohama Minami Kyosai Hospital, Yokohama, Japan

Background: Remitting seronegative symmetrical synovitis with pitting oedema (RS3PE) syndrome is a rare inflammatory arthritis, characterised by absence of rheumatoid factor, symmetrical distal synovitis, pitting oedema of the hands and feet.

In recent years the use of dipeptidyl peptidase-4 (DPP4) inhibitor has increased and some reports have described the association of RS3PE syndrome with DPP4 inhibitor.

Objectives: : We have tried to investigate the association of RS3PE syndrome with DPP4 inhibitor in our hospital.

Methods: : In Japan DPP4 inhibitor was released in December 2009, so we retrospectively analysed background, treatment and clinical course of 25 patients with RS3PE syndrome diagnosed between December 2009 and December 2016 in our hospital. We divided them in two groups according to DPP4 inhibitor prescription and compared two groups.

Results: : Our cases included 18 males and 7 females, and the mean age of RS3PE syndrome onset was 76 years old. The mean follow-up period was 32.5 months. Six patients had diabetes mellitus and DPP4 inhibitor was prescribed in five of six patients (83.3\%). (sitagliptin 3 cases, teneligliptin 1 case, alogliptin 1case). The duration of RS3PE syndrome onset after DPP4 inhibitor prescription was mean 22.9 months, and two cases developed within a half year, two cases after two years.

Compared with non DPP4 inhibitor group, the mean age of RS3PE syndrome onset was significantly low (70 vs $78.5, \mathrm{p}=0.023$ ), and HbA1c (NGSP) was high (7.3\% vs $6.02 \%, p=0.00022)$ in DPP4 inhibitor group.

The occurrence of flare was four cases in non DPP4 inhibitor group and zero in DPP4 inhibitor group, but was not statistically different $(p=0.275)$. Other clinical features were not significantly different.

Abstract AB1166 - Table 1. Clinical characteristics of the patients

\begin{tabular}{lccr}
\hline \multicolumn{1}{c}{ Characteristics } & $\begin{array}{c}\text { DPP-4 inhibitor } \\
(\mathrm{N}=5)\end{array}$ & $\begin{array}{c}\text { non DPP-4 inhibitor } \\
(\mathrm{N}=20)\end{array}$ & P value \\
\hline Mean age - yr & $70( \pm 7.91)$ & $78.5( \pm 6.61)$ & 0.023 \\
Male sex - no.(\%) & $5(100 \%)$ & $13(65 \%)$ & 0.119 \\
CRP, mg/dl & $7.97( \pm 5.08)$ & $7.45( \pm 5.86)$ & 0.86 \\
HbA1c (NGSP), \% & $7.3( \pm 0.68)$ & $6.02( \pm 0.57)$ & 0.00022 \\
Medications & & & \\
MTX & $2(40 \%)$ & $9(45 \%)$ & \\
$\quad$ Patients, no.(\%) & $8( \pm 0)$ & $7.33( \pm 1)$ & 0.081 \\
Dose, mg/week & & & \\
Oral prednisolone & $5(100 \%)$ & $18(90 \%)$ & \\
Patients, no.(\%) & $12( \pm 4.47)$ & $10.8( \pm 4.62)$ & 0.625 \\
$\quad$ Dose, mg/day & $0(0 \%)$ & $1(5 \%)$ & 0.61 \\
Malignancies - no.(\%) & $0(0 \%)$ & $4(20 \%)$ & 0.275 \\
Flare - no.(\%) & & & \\
\hline
\end{tabular}

Conclusions: : DPP4 inhibitor group was significantly younger than non DPP4 inhibitor group, and the possibility that DPP4 inhibitor contributed to the early onset of RS3PE syndrome was suggested.

\section{REFERENCES:}

[1] Oyama K, Taniguchi J, et al. Remitting seronegative symmetrical synovitis with pitting edema syndrome in individuals with type 2 diabetes mellitus or impaired glucose tolerance. Diabetes Res Clin Pract. 2015 Oct;110(1):e5-

[2] McCarty DJ, O'Duffy JD, et al. Remitting Seronegative Symmetrical Synovitis with Pitting Edema (RS3PE Syndrome). JAMA 1985; 254: 2763-2767.

Disclosure of Interest: None declared

DOI: 10.1136/annrheumdis-2018-eular.2829

\section{Diagnostics and imaging procedures}

\section{AB1167 METHOD COMPARISON OF AESKUSLIDES ANCA FOR THE DIAGNOSIS OF ANCA-ASSOCIATED VASCULITIS}

A. Lerner ${ }^{1}$, T. Matthias ${ }^{1}$, K. Prager ${ }^{2}$, T. Barth $^{2}$, S. Reuter ${ }^{2}$, J. Bär ${ }^{2}$, S. Bush ${ }^{2}$, M. Walle ${ }^{2} .{ }^{1}$ RandD, AESKU.KIPP Institute; ${ }^{2}$ RandD, Aesku. Diagnostics GmbH and Co. KG, Wendelsheim, Germany

Background: AESKUSLIDES ANCA is an indirect immunofluorescence assay used to detect anti-neutrophil cytoplasmic autoantibodies (ANCA) in human serum. This in vitro diagnostic assay is used as an aid for the diagnosis of ANCA associated vasculitis (AAV) in conjunction with other clinical and laboratory findings.

Methods: A method comparison of ethanol and formalin fixed granulocytes was carried out between AESKUSLIDES ANCA (AESKU. Diagnostics) and the NOVA Lite ANCA of INOVA. 507 clinical serum samples (comprising 135 serum samples from patients with $A A V$ and 375 samples from patients with other diseases) were analysed by standard IFA protocols. Results were obtained by manual processing and reading.

Results: In this cohort, AESKUSLIDES ANCA Ethanol slides show higher sensitivities (48.5\% vs. $36.4 \%$ ) and specificities (69.3\% vs. $55.2 \%$ ) compared to INOVA. AESKUSLIDES ANCA Formalin slides show higher sensitivities $(50.0 \%$ vs. $37.9 \%)$ and similar specificities $(90.7 \%$ vs $91.5 \%)$ compared to INOVA.

Conclusions: AESKUSLIDES ANCA Ethanol showed higher diagnostic sensitivity $(48.5 \%)$ and specificity $(69.3 \%)$ compared to the predicate assay NOVA Lite provided by INOVA $(36.4 \%, 55.2 \%)$. This is due to the fact, that AESKU assay detects more positives in the AAV cohort, and less positives in the other disease groups. AESKUSLIDES ANCA Formalin showed a diagnostic sensitivity (50.0\%) compared to the predicate assay NOVA Lite provided by INOVA (37.9\%). However, the diagnostic sensitivity was comparable between the two $(90.7 \%$ vs 91.5\%).

Disclosure of Interest: None declared

DOI: 10.1136/annrheumdis-2018-eular.6319

\section{AB1168 IS MY CLINICAL EXAMINATION ADEQUATE TO EVALUATE DISEASE ACTIVITY IN CHILDREN WITH JUVENILE IDIOPATHIC ARTHRITIS (JIA)? A COMPARATIVE ASSESSMENT OF CLINICAL AND ULTRASOUND (US) EXAMINATION OF 40 KNEES AND ANKLES IN 10 CHILDREN WITH JIA}

A. Shivpuri, M. Agarwal, S. Sawhney. PEDIATRIC RHEUMATOLOGY, SIR GANGA RAM HOSPITAL, NEW DELHI, India

Background: JIA is the commonest rheumatologic disease of childhood with a quoted prevalence of 1:1000. Assessment of children with JIA includes:Clinical, laboratory and more recently US evaluation of joints. Rapid attainment of inactive disease is critical for a good long term outcome. There is a debate in the rheumatology community about added advantage of US examination over clinical assess ment of joints. This study was done to compare clinical versus US evaluation of knees and ankles in children with JIA.

Objectives: 1 . To clinically examine and scan knees and ankles of 10 children with JIA

2. To determine sensitivity and specificity of clinical examination of knees and ankles vis a vis US scan findings

3. To compare results of knee and ankle examination both clinical and US

Methods: 1.10 consecutive children with JIA were evaluated for active arthritis of knees and ankles and documented on a pre designed proforma.

2. Children were then examined with US on same day by same observer and joint effusion and or synovitis was captured using an E9/S7 GE machine with a linear transducer 6-15 $\mathrm{MHz}$.

Results: 10 children aged $6-16$ years, $(6 \mathrm{~F}$ and $4 \mathrm{M})$ who attended the out-patient paediatric rheumatology clinic at our hospital with JIA were clinically evaluated and US examination performed on same day by same examiner with prior consent. Using the standard ESSR protocols, US knee and ankle joints were examined in longitudinal view and if any effusion or synovitis detected was confirmed on transverse view. The presence of grey scale synovial proliferation or anechoic effusion was taken as a positive US finding.

Knee-Sensitivity of clinical examination- $100 \%$, specificity- $91.7 \%$.

Ankles-Clinically 8 had swollen ankle, On US only 5 children had swollen ankle (tibio talar TT) joint. 3 who had a swollen ankle clinically had no synovial hypertrophy or effusion in the TT joint but had tenosynovitis(TS) of adjacent tendons: 1 each has a TS of the Extensor Digitorum Longus, Tibialis Anterior, Tibialis Posterior. Sensitivity- $60 \%$ and specificity- $66.7 \%$. 
Abstract AB1168 - Table 1. Clinical \& US examination details on knees \& ankles of 10 children (40 joints)

\begin{tabular}{|c|c|c|c|c|c|c|c|c|c|}
\hline Patients & Diagnosis & $\begin{array}{l}\text { Rt Knee } \\
\text { Clinical }\end{array}$ & $\begin{array}{c}\text { Rt Knee } \\
\text { US }\end{array}$ & $\begin{array}{l}\text { Lt Knee } \\
\text { Clinical }\end{array}$ & $\begin{array}{c}\text { Lt Knee } \\
\text { US }\end{array}$ & $\begin{array}{c}\text { Rt Ankle } \\
\text { Clinical }\end{array}$ & $\begin{array}{c}\text { Rt Ankle } \\
\text { US }\end{array}$ & $\begin{array}{l}\text { Lt Ankle } \\
\text { Clinical }\end{array}$ & Lt Ankle US \\
\hline$\overline{P t} 1$ & SJIA & + & + & + & + & - & + & + & + \\
\hline Pt 2 & SJIA & - & - & - & - & + & + & - & - \\
\hline Pt 3 & ERA & - & - & - & - & - & - & + & $\begin{array}{c}- \\
\text { TP } \\
\text { tenosynovitis }\end{array}$ \\
\hline Pt 4 & ERA & - & - & - & - & - & - & + & $\begin{array}{c}- \\
\text { TA } \\
\text { tenosynovitis }\end{array}$ \\
\hline Pt 5 & PJIA & - & - & - & - & - & + & - & - \\
\hline Pt 6 & PJIA & + & + & + & + & - & - & - & - \\
\hline Pt 7 & ERA & + & + & - & - & + & EDL TS + & - & - \\
\hline Pt 8 & ERA & - & - & - & - & + & - & - & - \\
\hline Pt 9 & PJIA & + & + & + & + & - & - & + & + \\
\hline Pt 10 & PJIA & + & + & + & - & + & - & - & - \\
\hline
\end{tabular}

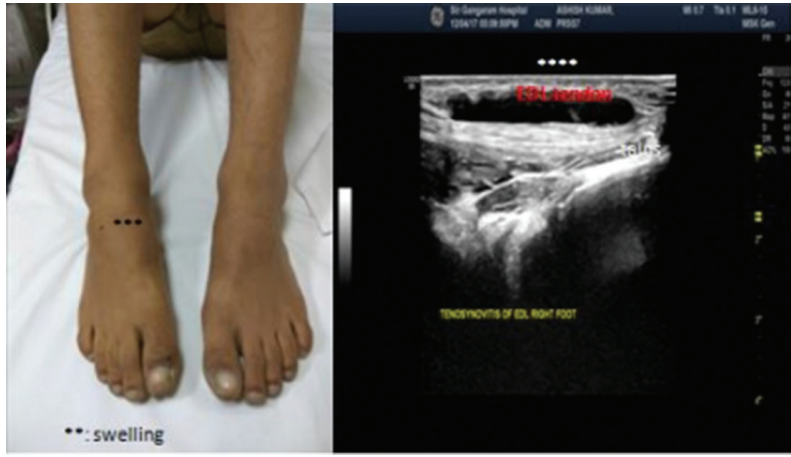

Abstract AB1168 - Figure 1

Conclusions: With gold standard as US for detection of synovitis, sensitivity of clinical examination-100\% for knee, specificity-91.7\%. For clinical examination of ankles, sensitivity-60\% and specificity- $66.7 \%$ suggesting possibility of mistaking an adjacent tendon sheath swelling for a TT joint disease. This has important implications for systemic therapies and intervention. The US is a valuable addition to clinical examination of the joints. Clinical examination alone in this pilot study of 10 children with JIA is inadequate to assess disease of the ankles. Evidence shows US to be superior to the clinical examination alone, but the lack of validated US findings, scoring systems and treatment algorithms exposes the need for further research.

Disclosure of Interest: None declared

DOI: 10.1136/annrheumdis-2018-eular.5254

\section{AB1169 CAN ULTRASOUND-DETECTED SYNOVITIS PREDICT RADIONUCLIDE SYNOVECTOMY EFFICACY IN CHRONIC INFLAMMATORY RHEUMATISM?}

A.S. Amouzougan ${ }^{1}$, H. Marotte ${ }^{2}$, K. Boussoualim ${ }^{1}$, L. Mijola ${ }^{1}$, P. Collet ${ }^{1}$, B. PallotPrades $^{1}$, N. Prévot-Bitot ${ }^{3}$, F.-G. Barral ${ }^{4}$, T. Thomas ${ }^{2} .{ }^{1}$ Rheumatology, Universital Hospital of Saint-Etienne; ${ }^{2}$ Rheumatology, Inserm 1059, Universital Hospital of Saint-Etienne; ${ }^{3}$ Nuclear Medecine; ${ }^{4}$ Radiology, Universital Hospital of SaintEtienne, Saint-Etienne, France

Background: The better management of inflammatory joint diseases, including biological treatments, has not eliminated in the clinical practice the persistence of chronic inflammatory monoarthritis despite local glucocorticosteroids (GC) injection and optimal systemic treatment. No therapeutic consensus was proposed in this clinical situation. In addition, radionuclide synovectomy (RS) was proposed with no clear benefit-risk effect. However, it has been shown that ultrasounddetected residual synovitis is frequent and predictable to relapse and structural progression in rheumatoid arthritis patients.

Objectives: We explored ultrasound-detected synovitis predictive value of response to RS in chronic inflammatory monoarthritis.

Methods: A monocentric prospective study was performed including unclassified monoartrhitis, rheumatoid arthritis, spondyloarthritis, and lupus between January 2012 and December 2017. All patients already received GC intra-articular injections $(\mathrm{GCl})$ and were treated in particular by cs or bDMARDS. On the day of the $\mathrm{RS}$ performed by a radiologist under radioscopic control, all patients had an articular power Doppler $(\mathrm{PD} ; 0-3)$ with greyscale $(\mathrm{GS} ; 0-3)$ ultrasonography with a MyLab 60 - EASAOTE, by 2 experimented sonographers.
Primary endpoint (EP) was subjective overall improvement $>50 \%$ without of any $\mathrm{GCl}$ and/or surgical management at 6 months (M).

Chi-square test was used to check the difference between groups.

Results: Data from 23 patients, 17 women and 6 men, with mean age $54 \pm 14$ years were analysed. Eleven RA $(45.5 \% R F$ +or $A C P A+), 3$ pSpA, 2 axSpA HLA B27+, 1 Lupus, and 6 unclassified monoartrhitis ( $F R$ and $A C P A-)$. Histological analysis of the synovium in 7 patients concluded to chronic nonspecific synovitis. Twenty eight joints were treated. Of them, 25 were coted US GS $>2$ and/or DP $\geq 2$. None had US GS=0 and $D P=0$. Effusion on US exam was reported in 24 joints.

On X-ray, $46.4 \%$ of patients had joint space narrowing and/or erosion. ESR or CRP increased in $43.5 \%$. Forty five previous $\mathrm{GCl}$ were declared (Cortivazol or triamcinolone hexacetonide), with a median at $2 .^{1-6}$

Patients were treated with methotrexate, $n=16$ (69.6\%), hydroxychloroquine, $n=1$, bDMARDS, $n=11$ (48\%), oral GC, $n=8(35 \%)$ and non-steroidal anti-inflammatory drug, $\mathrm{n}=6(26 \%)$.

At $\mathrm{M} 6$ and $\mathrm{M} 12,64.6 \%$ of patients reached the EP. One patient reached the EP only at M12 and another one only at M6. No significant differences were observed between groups in terms of PDUS (DP $\geq 2$ vs $D P \leq 1$ ), unclassified monoartrhitis, and joint space narrowing and/or erosion.

Only one patient had pain exacerbation 24 hour after RS followed by a quick recovery.

Conclusions: In chronic inflammatory monoarthritis, PDUS was not predictive of clinical outcome after RS. However, this intra-articular procedure appeared effective in either unclassified or classified monoarthritis or in presence of radiographic joint lesions.

Disclosure of Interest: None declared

DOI: 10.1136/annrheumdis-2018-eular.6850

\section{AB1170 1 FIRST RESULTS OF THE RHEUMATOID ARTHRITIS HANDSCAN REGISTRY LEEUWARDEN}

A. Al Hasan, R. Bos, N. Veeger, D. Zhang, L. Hendriks, F. Wink, A. Schilder, F. Reimann, K. Bergsma. MEDISCH CENTRUM LEEUWARDEN, Leeuwarden, Netherlands

Background: The handscan is a new technologic device which uses diffuse optical transmission in combination with blood flow modulation. It is a non-invasive measurement of joint inflammation potentially more sensitive than the clinical evaluation of the joints by a rheumatologist[. ${ }^{1}$ However, more clinical data is necessary before this new device can be implemented in the daily clinical practice. Objectives: This study investigates the additional value of the handscan in decision making in the daily practice for patients with rheumatoid arthritis.

Methods: At our outpatient clinic we started a registry for rheumatoid arthritis patients with a disease duration of at least two years. During this period, a hands can will be made for all patients before every regular visit. Both the patient and the treating rheumatologist will be blinded to the handscan outcome. Primary outcome is the association between DAS28 score and the total optical score (TOS) of the handscan per visit.

Results: The study started in December 2017, until now 100 patients are included. The mean age was 61.1 years, the mean disease duration at time of inclusion 11.2 years, $67 \%$ were rheumatoid factor positive, $51 \%$ were anti-CCP positive. In figure 1 we show the association between DAS28 and the TOS in a lin ear model.

Currently there is no validated cut off point for the TOS (negative or positive score for inflammation). In our group of 100 patients the median TOS was 10 , the most discriminating TOS was found to be 17 using chi-square test as depicted in table 1. 